\title{
Association between Maternal Antibodies to the External Envelope Glycoprotein and Vertical Transmission of Human T-Lymphotropic Virus Type I
}

\author{
Maternal Anti-env Antibodies Correlate with Protection in Non-Breast-fed Children
}

\author{
Shigeo Hino, * Shigeru Katamine, ${ }^{\ddagger}$ Tsutomu Miyamoto, ${ }^{\ddagger}$ Hiroshi Doi, ${ }^{5}$ Yoshiro Tsuji, ${ }^{5}$ Toru Yamabe," Jonathan E. Kaplan, \\ Donna L. Rudolph,' and Renu B. Lal' \\ * Department of Virology, Faculty of Medicine, Tottori University, Yonago 683, Japan; ${ }^{\ddagger}$ Department of Bacteriology, Nagasaki \\ University School of Medicine, Nagasaki 852, Japan; ${ }^{8}$ Department of Pediatrics, Nagasaki University School of Medicine, Nagasaki 852, \\ Japan; "Department of Gynecology and Obstetrics, Nagasaki University School of Medicine, Nagasaki 852, Japan; and 'Retrovirus \\ Diseases Branch, Division of Viral and Rickettsial Disease, National Center for Infectious Diseases, Centers for Disease Control and \\ Prevention, U.S. Department of Health and Human Services, Atlanta, Georgia 30333
}

\begin{abstract}
Vertical transmission of human T-lymphotropic virus type I (HTLV-I) depends primarily on breast-feeding; substitution of bottle-feeding has reduced the transmission rate from $20 \%$ in breast-fed children to $3 \%$ among bottle-fed. To determine the correlates of transmission for long breast-feeding ( $\geq 6 \mathrm{mo}$ ), short breast-feeding ( $<6 \mathrm{mo}$ ), and bottlefeeding mothers, the antibody titers of transmitter ( $T$ ) mothers and non-transmitter (nT) mothers were analyzed by using synthetic and recombinant epitopes representing the immunodominant epitopes of gag (Gag1a, r24), env (Env1/5, MTA1, RE3), and tax (Tax8/22-24) proteins. Seroreactivity to gag and tax epitopes was not significantly different except for anti-r24 antibody titer, which was significantly higher among $T$-mothers (geometric mean 134) when compared with $\mathrm{nT}$-mothers (62) in the long-feeding group $(P<0.001)$. Profiles of antibody titers against env epitopes were different. Within the long-feeding group, Env1/5, MTA1, and RE3 titers were significantly higher among $T$-mothers $(258,1,476$, and 738 , respectively) when compared with nT-mothers $(106,279$, and 320 , respectively) ( $P<0.01$ for all three epitopes). In contrast, within the bottle-feeding group, antibody titers to Env1/5 (269) and RE3 (418) among nT-mothers were significantly higher than those among $\mathrm{T}$-mothers ( 80 and 113 , respectively) ( $P$ $<0.01)$. These data confirm that high-titered anti-HTLV$I$ antibodies in the long-feeding group correlate with milkborne transmission of HTLV-I and, more importantly, imply that maternal anti-env antibodies may reduce the risk of non-milkborne infection. (J. Clin. Invest. 1995. 95:29202925.) Key words: HTLV-I • vertical transmission • passive immunization • antibody titers
\end{abstract}

Address correspondence to Renu B. Lal, Retrovirus Diseases Branch, Mail Stop G-19, DVRD, NCID, CDC, Atlanta, GA 30333. Phone: 404-6391036; FAX: 404-639-1174; E-Mail: RBL3@CIDDVD1.EM.CDC.GOV.

Received for publication 28 June 1994 and in revised form 23 November 1994.

1. Abbreviations used in this paper: APP, ATL prevention program; HTLV-I, human T-lymphotropic virus type I; nT-mothers, non-transmitter mothers; T-mothers, transmitter mothers.

The Journal of Clinical Investigation, Inc.

Volume 95, June 1995, 2920-2925

\section{Introduction}

Human T-lymphotropic virus type I (HTLV-I) ${ }^{1}$ is endemic in southwestern Japan, the Caribbean Islands, and certain parts of Africa and is etiologically linked with adult $\mathrm{T}$ cell leukemia/ lymphoma and HTLV-I-associated myelopathy $(1,2)$. The major routes of transmission for HTLV-I include sexual contact, blood transfusion, and mother to child $(1,3)$. Seroepidemiologic studies of pregnant women and their children, as well as oral inoculation of carrier mothers' breast milk into common marmosets, indicates that breast-feeding plays an important role in the transmission of HTLV-I $(4,5)$. In 1987, the ATL Prevention Program (APP) was initiated in Nagasaki, Japan, to determine whether screening and counseling of pregnant women could prevent transmission of HTLV-I by breast-feeding (6). Follow-up studies have shown that $\sim 20 \%$ of breast-fed children and only $3 \%$ of bottle-fed children born to HTLV-I-carrier mothers become infected $(7,8)$. The observation that some breast-feeding and non-breast-feeding carrier mothers transmit HTLV-I while others do not implies that there may be mechanisms other than feeding that affect the transmission of HTLVI from mother to child.

Several maternal risk factors for mother-to-child transmission of HTLV-I have been proposed: these include high levels of HTLV-I-positive lymphocytes in breast milk $(9,10)$, high proviral load in peripheral blood (11), high titer of anti-HTLVI antibody (12), and anti-tax antibodies (13, 14). However, these studies on antibody titers have not identified the specific epitopes within the HTLV-I genome that might correlate with mother-to-child transmission. Thus, analysis of maternal HTLV-I antibodies directed against various antigens coded for by the HTLV-I genome may provide clues as to their potential use as markers for mother-to-child transmission, or alternatively, a protective role of these antibodies.

The APP cohort provided us a unique opportunity to assess the relationship between antibody reactivities and HTLV-I transmission. In the search for possible associations between the presence of specific antibodies and mother-to-child transmission of HTLV-I, we analyzed the antibodies in sera of mothers who transmitted HTLV-I (transmitter; T-mothers), and mothers who did not (non-transmitter; nT-mothers), using various peptides and recombinant proteins representing the immunodominant epitopes of HTLV-I. Our results indicate that hightitered maternal env antibodies are associated with transmission in long-term ( $\geq 6 \mathrm{mo}$ ) breast-fed children and that high-titered maternal antibodies to certain epitopes of external glycoproteins appear to be protective in bottle-fed children. 


\section{Methods}

APP. Nagasaki Prefecture, one of 47 prefectures in Japan, is located in southwestern Japan on the island of Kyushu and has a population of $\sim 1.5$ million. APP was implemented in this prefecture in 1987. Informed consent was obtained from each mother, and the study was approved under the guidelines of Nagasaki University. Pregnant women were offered serologic testing for HTLV-I, and infected women were counseled to refrain from breast-feeding. Since 1987, 15,000 women, representing $>85 \%$ of all pregnant women in the prefecture, have been screened annually. The HTLV-I prevalence in this group is $\sim 4 \%$. As of December 1992, > 3,000 seropositive mothers were enrolled in the study.

At enrollment and thereafter, blood samples were taken from mothers in the last trimester of each pregnancy. After delivery, mothers were requested to bring their newborns to one of 17 designated pediatric units in the prefecture at $6,12,18,24$, and 36 mo of age. Approximately one-half of the mothers showed up for follow-up testing; on these visits information on breast-feeding was collected. Only children with a serum sample taken at $\geq 18$ mo were considered eligible for purposes of classifying their mothers as T-mothers or nT-mothers. As of December 1992 , records were available for 1,253 such children born to 889 mothers. In addition, 98 children up to $13 \mathrm{yr}$ old, born to the same mothers before APP, had also been studied. Information on their breast-feeding status was also obtained.

Serologic testing for HTLV-I. Serum specimens from all participating subjects (mothers and children) were tested by gelatin particle agglutination assay (Fuji-Rebio, Tokyo, Japan) at commercial laboratories. All positive and indeterminate samples were sent to the Department of Bacteriology, Nagasaki University School of Medicine, where they were tested by particle agglutination and by an indirect immunofluorescence assay that used a mixture of MT-2 and CEM cells. Serum specimens with positive results in both assays were scored positive; those with positive results in one assay, or with indeterminate results in either assay, were tested further by immunoblot (15).

To confirm the specificity of serologic tests, randomly selected specimens from 30 seropositive mothers and 26 seropositive children ( $\geq 18$ mo old) were tested at the Centers for Disease Control and Prevention by a modified Western blot assay incorporating recombinant env proteins (HTLV 2.3; Genelabs Diagnostics Inc., Redwood, CA) (16). A serum specimen was designated HTLV-I/II-positive if antibody reactivity was detected to gag p24 and env r21e or rgp46. All specimens that were confirmed to be HTLV-I/II positive in the APP were also positive at the Centers for Disease Control and Prevention.

Selection of HTLV-I-infected mothers for the study. Mothers were selected based on the presence of infection in one or more of their children (transmitters) or absence of infection in all eligible children (non-transmitters). All T-mothers whose blood samples were available in frozen stock were included in the study. The T-mothers were further classified based on the feeding history of the child: breast-fed for $\geq 6$ mo (long-feeding), or for $<6$ mo (short-feeding), or bottle-fed. One mother who transmitted HTLV-I to both a long-feeding and a bottlefed child was deleted from the study.

Many nT-mothers had eligible children in different feeding categories because of the implementation of APP. Mothers with more than one eligible breast-fed child were classified according to the child with the longest breast-feeding history. nT-mothers were selected using computer-generated random numbers so that the ratio of nT- to T-mothers in each feeding category would be $\sim 1.5: 1$.

Maternal antibodies to synthetic peptides and recombinant proteins. The synthetic peptides derived from the gag (Gag-1a ${ }^{102-117}$, PPSSPTHDPPDSDPQI), env (Env1 ${ }^{191-214}$, LPHSNLDHILEPSIPWKSKLLTLV, and Env $5^{242-257}$, SPNVSVPSSSSTPLLY), and $\operatorname{tax}$ (Tax $8^{106-125}$, LQAMRKYSPSRNGYMEPTLG; Tax $22^{316-335}$, PISLLFNEKEADDNDHEPQI; Tax $23^{331-350}$, HEPQISPGGLEPPSEKHFRE; and Tax24 $4^{336-353}$, SPGGLEPPSEKHFRETEV) proteins of HTLV-I were synthesized by 9-fluorenylmethyloxycarbonyl (FMOC) chemistry (see Fig. 1 for approximate location in the HTLV-I genome) (17-19). We have reported previously that a cocktail assay composed of two or more peptides results in enhanced sensitivity of antibody detection as compared with a single peptide. Therefore, we used an equimolar ratio of Env1 and Env5 for env detection (18) and Tax8, Tax22, Tax23, and Tax 24 for tax detection (19). Recombinant proteins included r24, which comprises the entire p2 $4^{\text {gag }}$ protein of HTLV-II (Intracel Corp., Cambridge, MA) and which reacts with anti-p24 antibodies (both HTLV-I and HTLV-II) in human sera (data not shown). Recombinant proteins also included MTA1, which comprises the central region of the external glycoprotein of HTLV-I (amino acids [a.a.] 162-209) (kindly provided by L. Chan, Genelabs Diagnostics Inc.) (16); and RE3, which comprises the COOH-terminal half of the external glycoprotein of HTLV-I (a.a. 165-306) (Repligen Corp., Cambridge, MA) (20). A whole viral lysate spiked with recombinant transmembrane protein (r21e) of HTLV-I was also included to determine the antibodies to whole virus proteins (21). Antibodies to these synthetic peptides and recombinant proteins were determined as described previously $(18,19)$. Seropositivity was defined as any value greater than the mean of the normal controls +2 standard deviations. All specimens were coded without knowledge of the mother's category.

Statistical analysis. Analysis proceeded using six categories of mothers, according to transmitter/non-transmitter and feeding status. Each mother was included in only one category. Antibody titers were expressed by reciprocals of the highest dilution that gave positive results in the Env1/5, MTA1, RE3, and r21e-spiked HTLV-I assays after 2fold dilutions starting from 1:20. Assays of Gag-1a, r24, and Tax8/2224 assays were performed at a dilution of 1:20. Antibody titers in these assays were computed from a dilution curve of pooled standard positive sera. For calculation, negative sera were scored as one tube earlier than the first dilution (1:10), and overscaled ones were scored as the last dilution. Antibody titers were converted into logarithms for computation, and the geometric mean and $95 \%$ confidence intervals (determined by twice the standard deviation) were calculated back into linear scale. Statistical analyses were performed after all the immunological data were obtained by using nonparametrical analysis of variance by the Bonferroni/Dunn method.

\section{Results}

Classification of HTLV-I-seropositive mothers. Of 889 mothers whose children were tested at the ages of at least $\geq 18 \mathrm{mo}$, we selected 169 mothers, including $66 \mathrm{~T}$-mothers and 103 randomly sampled nT-mothers. All mothers were of Japanese descent. These mothers were further categorized based on the feeding history. Of the $66 \mathrm{~T}$-mothers, 32 breast-fed their babies for $\geq 6$ mo (long-feeding), 12 breast-fed for $<6$ mo (short-feeding), and 22 bottle-fed their babies (Table I). Of the 103 nT-mothers, 56 were in the long-feeding category, 19 were in the shortfeeding category, and 28 were in the bottle-feeding category. The intervals between sampling of the mother and birth of the child were greater in breast-feeding than in bottle-feeding mothers because of inclusion of mothers who breast-fed older children. However, within each feeding category, the ages of the mothers and the intervals between sample of the mother and birth of the child in T- and nT-groups were highly comparable (Table I).

Comparison of maternal antibody levels in the long-feeding group. The seroreactivity and antibody titers were compared in $\mathrm{T}$ - and nT-mothers using whole virus proteins spiked with $\mathrm{r} 21 \mathrm{e}$ protein (HTLV-I) (Table II). Serum specimens from all mothers, except for one nT-mother, reacted in the assay. Comparison of anti-HTLV-I titers demonstrated significantly higher levels among T-mothers (mean: 944; 95\% CI: 80-11,092), as compared with nT-mothers (mean: 385; CI: 30-4,966) $(P$ $=<0.001$ ) (see Fig. 2). The antibody reactivities to gag 
Table I. Demographics and Epidemiological Background of Mothers Tested

\begin{tabular}{lccccc}
\hline Feeding category & Transmission & $\begin{array}{c}\text { No. mothers } \\
\text { eligible }\end{array}$ & $\begin{array}{c}\text { No. mothers } \\
\text { sampled }\end{array}$ & $\begin{array}{c}\text { Age of mothers at } \\
\text { sampling }\end{array}$ & $\begin{array}{c}\text { Interval between sampling } \\
\text { of mother and birth of } \\
\text { child in years* }\end{array}$ \\
\hline & & & & & \\
mean $(95 \% C I)$ & & & \\
mean (95\% CI) \\
$>6$ mo (long) & Yes & 39 & 32 & $30.6(22.2-39.1)$ & $-3.1^{\ddagger}(-9.0-2.7)$ \\
& No & 186 & 56 & $30.5(22.7-38.3)$ & $-2.6(-7.3-2.0)$ \\
$<6$ mo short & Yes & 12 & 12 & $31.3(24.1-38.6)$ & $-1.8(-6.7-3.1)$ \\
Bottle & No & 141 & 19 & $30.6(23.4-37.8)$ & $-2.2(-5.5-1.1)$ \\
& Yes & 25 & 22 & $30.2(23.1-37.3)$ & $0.2(-1.4-1.8)$ \\
& No & 486 & 28 & $28.1(19.8-36.4)$ & $1.2(-2.4-4.7)$ \\
\hline
\end{tabular}

* Not significant $(P>0.05)$ by ANOVA (Bonferroni/Dunn) in each feeding category. ${ }^{\ddagger}$ The minus sign indicates that child was born before blood sampling of the mother.

(Gag1a and r24) and $\operatorname{tax}$ (Tax8/22-24) epitopes were 72, 100, and $22 \%$ among T-mothers, and 66,91 , and $16 \%$ among $\mathrm{nT}$ mothers, respectively (Table II). While antibody titers to Gagla and Tax8/22-24 were not significantly different between $\mathrm{T}$ and non- $T$ groups, antibody titers to r24 were significantly higher in the T-group (mean: 134; CI: 21-867) when compared with the nT-group (mean: 62; CI: $<20-531)(P<0.001)$.

While seroreactivity against $e n v$ epitopes (Env1/5) was not significantly different among $\mathrm{T}$ - and nT-groups, antibody titers to this epitope were significantly higher in the T-group (mean:

Table II. Analysis of Seropositivity and Antibody Titers to Immunodominant Epitopes of Structural and Regulatory Proteins of HTLV-I in Transmitter vs Nontransmitter Mothers

\begin{tabular}{|c|c|c|c|c|c|}
\hline \multirow[b]{2}{*}{ Epitope regions } & \multicolumn{2}{|c|}{ Seroreactivity* } & \multicolumn{2}{|c|}{ Antibody titer } & \multirow[b]{2}{*}{$P$ value $^{\ddagger}$} \\
\hline & Transmitter & Nontransmitter & Transmitter & Nontransmitter & \\
\hline & No. pos/No. tested (\%) & No. pos/No. tested (\%) & mean $(95 \% C I)$ & mean $(95 \% C I)$ & \\
\hline \multicolumn{6}{|l|}{ Long-feeding group } \\
\hline HTLV-I & $32 / 32(100)$ & $55 / 56(98)$ & $944(80-11092)$ & $385(30-4966)$ & $<0.001$ \\
\hline Gagla & $23 / 32(72)$ & $37 / 56(66)$ & $67(<20-1734)$ & $44(<20-986)$ & NS \\
\hline $\mathrm{r} 24$ & $29 / 29(100)$ & $51 / 56(91)$ & $134(21-867)$ & $62(<20-531)$ & $<0.001$ \\
\hline $\operatorname{Tax} 8 / 22-24$ & $7 / 32(22)$ & $9 / 56(16)$ & $<20(<20-78)$ & $<20(<20-79)$ & NS \\
\hline Env1/5 & $32 / 32(100)$ & $52 / 56(93)$ & $258(21-3214)$ & $106(<20-1875)$ & 0.004 \\
\hline MTA1 & $29 / 29(100)$ & $47 / 55(85)$ & $1476(118-18408)$ & $279(<20-13583)$ & $<0.001$ \\
\hline RE3 & $29 / 29(100)$ & $55 / 55(100)$ & $738(106-5129)$ & $320(26-3899)$ & 0.005 \\
\hline \multicolumn{6}{|c|}{ Short-feeding group } \\
\hline HTLV-I & $12 / 12(100)$ & $19 / 19(100)$ & $285(29-2773)$ & $514(65-4064)$ & NS \\
\hline Gag1a & $8 / 12(67)$ & $14 / 19(74)$ & $41(<20-590)$ & $53(<20-841)$ & NS \\
\hline $\mathrm{r} 24$ & $11 / 11(100)$ & $18 / 19(95)$ & $64(<20-361)$ & $55(<20-251)$ & 0.031 \\
\hline Tax8/22-24 & $1 / 12(8)$ & $6 / 19(32)$ & $<20(<20-31)$ & $23(<20-312)$ & NS \\
\hline Env1/5 & $12 / 12(100)$ & $19 / 19(100)$ & $190(22-1618)$ & $286(22-3793)$ & NS \\
\hline MTA1 & $11 / 11(100)$ & $19 / 19(100)$ & $640(40-10233)$ & $617(48-7907)$ & NS \\
\hline RE3 & $11 / 11(100)$ & $19 / 19$ (100) & $193(<20-3327)$ & $445(41-4764)$ & NS \\
\hline \multicolumn{6}{|c|}{ Bottle-feeding group } \\
\hline HTLV-I & $22 / 22(100)$ & $28 / 28(100)$ & $374(32-4355)$ & $640(97-4227)$ & NS \\
\hline Gagla & $10 / 22(45)$ & $22 / 78(79)$ & $35(<20-703)$ & $58(<20-867)$ & NS \\
\hline $\mathrm{r} 24$ & $20 / 20(100)$ & $22 / 26(85)$ & $80(<20-392)$ & $56(<20-481)$ & NS \\
\hline $\operatorname{Tax} 8 / 22-24$ & $4 / 22(18)$ & $9 / 28(32)$ & $<20(<20-51)$ & $<20(<20-86)$ & NS \\
\hline Env1/5 & $16 / 22(73)^{*}$ & $28 / 28(100)$ & $80(<20-2449)$ & $269(30-2399)$ & 0.002 \\
\hline MTA1 & $20 / 20(100)$ & $26 / 26(100)$ & $453(<20-10715)$ & $693(51-9441)$ & NS \\
\hline RE3 & $20 / 20(100)$ & $26 / 26(100)$ & $113(<20-2767)$ & $418(33-5309)$ & $<0.001$ \\
\hline
\end{tabular}

* Comparisons made between seroreactivity in transmitters vs nontransmitters using $\chi^{2}$ test demonstrated differences to be nonsignificant for all comparisons $(P>0.05)$, except Env-1/5 in the bottle-feeding group, where the $P$ value was $0.012 .{ }^{\ddagger}$ Analysis of variance between antibody titers by Bonferroni-Dunn $(P<0.05)$ method. 


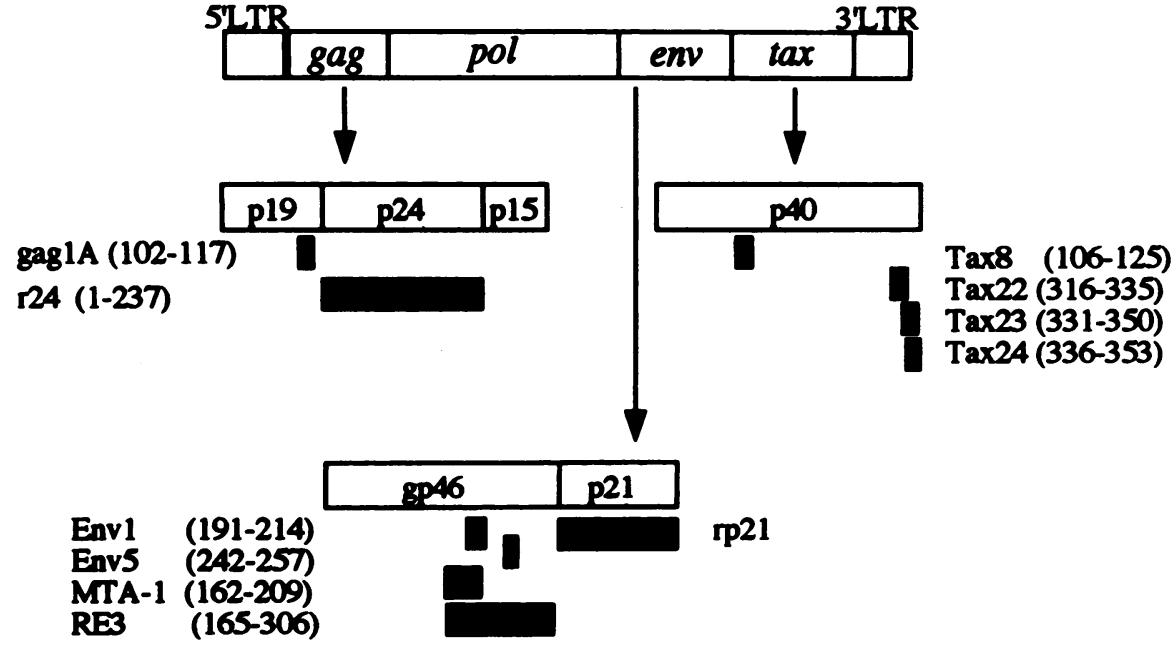

Figure 1. Location of immunodominant $\mathrm{B}$ cell epitopes within the HTLV-I genome, as represented by synthetic and recombinant proteins. The filled boxes represent approximate location and size of the epitope studied.
258; CI: $21-3,214$ ) as compared with the nT-group (mean: 106; CI: $<20-1,875)(P=0.004)$. Since Env1 and Env5 represent immunodominant epitopes located at the central region and carboxyl terminus of the external glycoprotein of HTLV-I, we next determined whether immune reactivity among T-mothers was restricted to a specific epitope. We used two recombinant constructs-MTA-1, representing a.a. 162-209 which overlaps with synthetic Env-1 (a.a. 191-214); and RE3, representing a.a. 165-306, which overlaps with both Env1 and Env5 (a.a. 242-256) (Fig. 1). Seroreactivity to MTA-1 and RE3 ranged from 85 to $100 \%$ in both groups. However, antibody titers to both MTA-1 and RE3 were significantly higher in Tmothers (mean: 1,476 and 738; CI: $118-18,408$ and 1065,129, respectively) than the nT-mothers (mean: 279 and 320; CI: $<20-13,583$ and $26-3899$, respectively $)(P<0.001$ and $P=0.005$, respectively) (Table II and Fig. 2).

Comparison of maternal antibody levels in the short-feeding group. Analysis of maternal seroreactivity within the short-feeding group revealed no significant difference between the $\mathrm{T}$ - and nT-groups in either the whole virus protein assay or any of the epitope-based assays (Table II). Similarly, analysis of antibody titers in the short-feeding group did not reveal any differences and could be attributed to the fact that T-mothers in this category represent both breast-feeding and non-breast-feeding - related transmission (22).

Comparison of maternal antibody levels in the bottle-feeding group. Overall seroreactivity to HTLV-I, gag and tax epitopes, and the titers to gag epitopes were similar in T- and nTgroups (Table II). Although the titers to HTLV-I were higher in nT-mothers (mean: 640; CI: 97-4,227) than in T-mothers (mean: 374; CI: 32-4,355), this difference did not reach statistical significance.

Seroreactivity to env epitopes (MTA1, RE3) was $100 \%$ in both groups; however, seroreactivity to Env1/5 was significantly higher among nT-mothers $(28 / 28 ; 100 \%)$ than T-mothers $(16 / 22 ; 73 \%)(P=0.01)$. Analysis of anti-Env1/5 and RE3 titers demonstrated significantly higher levels among nTmothers (mean: 269; CI: 30-2,399, and mean: 418; CI: 335,309, respectively) than T-mothers (mean: 80; CI: $<20-$ 2,449; and mean: 113; CI: $<20-2,767$, respectively) $(P$ $=0.002$ and $P<0.001$, respectively) (Table II and Fig. 2). Anti-MTA1 titers were also higher in nT-mothers (mean: 693, CI: 51-9,441) than in T-mothers (mean: 453; CI: $<20-$ $10,715)$, but the difference was not statistically significant.

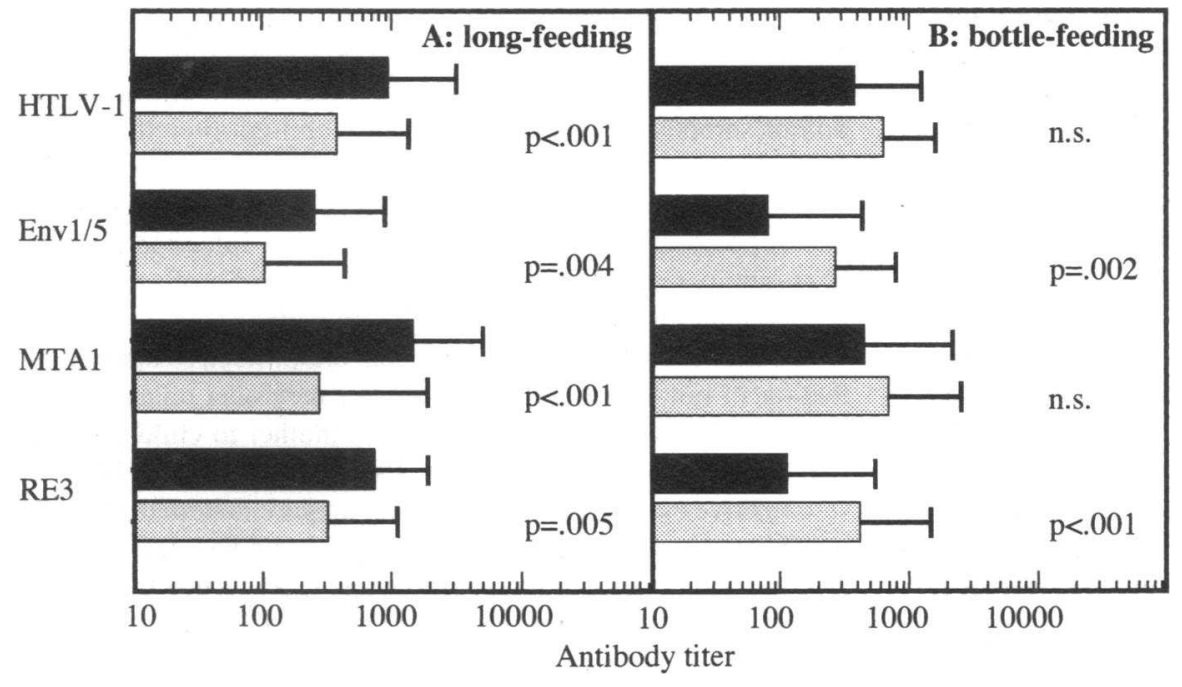

Figure 2. Antibody titers to HTLV-I and env epitopes (Env1/5, MTA1, and RE3) among transmitter (filled bars) and non-transmitter (dotted bars) mothers who breast-fed their babies for $\geq 6 \mathrm{mo}(A)$ and those who bottlefed their babies $(B)$. The statistical significance for each comparison is shown at the right side of each panel. 
Of the $33 \mathrm{~T}$-mothers originally in the long-feeding group, 20 had children who were bottle-fed and had samples available at $\geq 18 \mathrm{mo}$. One of these mothers (deleted from the study) also transmitted infection to a bottle-fed child; her HTLV-I, Env1/5, MTA1, and RE3 titers were 160, 40, 320, and 320, respectively. Of the $22 \mathrm{~T}$-mothers included in the bottle-feeding group, only one also had a child who was long-term breast-fed and had a specimen at $\geq 18 \mathrm{mo}$; this child was uninfected, and the mother's HTLV-I, Env1/5, MTA1, and RE3 titers were 80, 80,80 , and 40 , respectively.

\section{Discussion}

While mother-to-child transmission is the major route of transmission of HTLV-I in endemic areas (3-5), little is known about the immune responses that might affect such transmission. In this investigation, we have elucidated the serological basis for maternal immunity as it relates to either infectivity or protection from vertical transmission. We have examined this question by measuring specific binding of maternal serum samples to various immunodominant epitopes representing both the structural and regulatory proteins of HTLV-I (18-21). By using the model of mother-to-child transmission of HTLV-I infection, we have demonstrated that high antibody titers to HTLV-I and several epitopes from the envelope protein are associated with transmission to long-term breast-fed babies. We also have established an association between maternal antibodies to selected epitopes of external glycoproteins, in particular Env1/5 and RE3, and absence of infection in bottle-fed children.

There are some limitations in this study regarding classification of mothers. It is possible that the nT categories included mothers who would have been found to transmit HTLV-I if they had more children with serum specimens available at $\geq 18$ mo of age. However, such misclassification would decrease the difference between T- and nT-mothers. Another limitation was that nT-mothers who breast-fed an eligible child were so classified even if they bottle-fed younger eligible children. 26 such mothers were included in breast-feeding categories. However, addition of these $26 \mathrm{nT}$-mothers to the $28 \mathrm{nT}$-mothers in the bottle-feeding category still resulted in significantly higher env antibody titers in nT- versus T-mothers in the bottle-feeding category (data not shown). In the breast-feeding category, we included mothers whose classification was based on children born before the APP began. When such cases were nT-mothers, we cannot confirm that the mothers were carriers during these pregnancies. However, among 852 mothers who had also been tested in an earlier pregnancy, only 4 were seronegative at the earlier date. Thus, it is likely that the vast majority of, if not all, of these mothers were already infected during these earlier pregnancies. We also repeated our analyses, limiting them to mothers whose classification was based on children born during the APP. This resulted in a marked reduction in numbers of long-feeding mothers, and, in this group, T-mothers had higher env titers than nT-mothers in only the MTA assay $(P=0.03)$; however, similar trends were also observed in the Env1/5, RE3, and HTLV-I assays (data not shown). The numbers of bottlefeeding mothers and the results in this group were unchanged.

Analysis of anti-HTLV-I titers provided us a tool to determine the overall antibody status of $\mathrm{T}$ - and $\mathrm{nT}$-mothers in all three feeding categories, and analysis of immunodominant regions within gag, env, and tax allowed us to localize the regions that correlate with transmission or protection. The overall per- cent reactivities to gag and $e n v$ epitopes were similar to those in previous reports $(16,17)$. However, the seroreactivity to Tax peptides was significantly lower (8-32\%) than that previously reported for asymptomatic carriers from the United States $(62 \%)(19)$. Although the reason for the lower reactivities is not known, it could be related to sequence variations in this immunogenic region of tax, such as those found in a Melanesian isolate of HTLV-I (23).

Our finding of higher antibody titers to HTLV-I in T-mothers than nT-mothers in the long-feeding group corroborates previous reports in which high anti-HTLV-I titers were associated with increased frequency of mother-to-child transmission in long-fed babies $(12,24)$. The high-titered anti-HTLV-I presumably reflects high concentration of infected cells in peripheral blood as evidenced by high proviral load (25). At the epitope level, transmitters had significantly higher levels of antibodies to env epitopes, with no difference in gag and tax epitopes. These results corroborate previous results in which hightitered antibodies to env epitope sp4a1, which overlaps with the env epitopes tested here, were shown to correlate with a high risk of transmission in breast-fed babies (24). Our results further suggest that the COOH-terminal region of the external glycoprotein correlates with transmission. Taken together, these data imply that high-titered anti-HTLV-I antibodies, particularly those directed against the envelope protein, are associated with mother-to-child transmission, if the mother breast-feeds her child for $\geq 6 \mathrm{mo}$.

Of greater significance is the finding of high-titered antienv antibodies among $\mathrm{nT}$-mothers as compared with T-mothers in the bottle-feeding group. At the epitope level, antibody titers to both Env1/5 and RE3 were significantly higher among nTmothers than T-mothers. Anti-MTA1 titers also appeared to be higher in nT-mothers, but the difference was not statistically significant. Thus, levels of high-titered anti-env antibodies in the maternal sera may reduce the risk of infection in infants. The antibody pattern to specific env epitopes does not appear to reflect a general increase in antibody titers, since antibody titers to other antigens, including anti-HTLV-I and anti-r24, were comparable among $\mathrm{T}$ - and $\mathrm{nT}$-mothers. The central region of the external glycoprotein of HTLV-I has been shown to contain a cytotoxic and neutralizing epitope (26-28). Therefore, natural antibodies to these regions should be effective in neutralizing the virus and may provide some measure of natural immunity against HTLV-I. Thus, it is possible that mothers with high-titered neutralizing antibody can passively transfer high enough concentrations of maternal antibodies to protect their children from infection. It is conceivable that immunization of seropositive pregnant women with high-titered anti-env antibodies might be an effective means of boosting passively acquired maternal antibodies in infants. This hypothesis is further supported by the evidence that HTLV-I infection of newborn rabbits was prevented by the passive transfer of an immune IgG containing anti-HTLV-I antibody (29).

If high-titered anti-env antibodies are protective against infection in bottle-fed children, how are they also related to increased transmission of HTLV-I from mother to child in longfed babies? Previous study has shown that children born to seropositive carrier mothers passively acquire maternal antibodies prenatally; levels of these maternal antibodies decline over 3-6 mo and disappear at 6-9 mo of age (30). While the babies in the long-feeding group would still be breast-feeding on carrier mothers and ingesting HTLV-I-infected lymphocytes from the 
breast milk, the passively acquired high-titered anti-env antibodies would gradually disappear from circulation. This continuous ingestion of HTLV-I-infected lymphocytes could lead to HTLV-I infection in the babies (9). Indeed, lymphocytefacilitated infection of gut-epithelium has been demonstrated in vitro (31). We therefore believe that high-titered anti-HTLVI in T-mothers reflects a high proviral load that, in long-term breast feeders, results in increased probability of transmission when passively acquired maternal antibodies have disappeared from circulation.

This report is the first to suggest that antibody titers against HTLV-I are associated with vertical transmission of HTLV-I in both milkborne and non-milkborne pathways, but in different directions. Specifically, non-milkborne transmission of HTLVI was associated with lack of high-titered maternal antibodies to the env epitopes. Further study of the epitopes implicated herein may allow prediction of the humoral immune response that protects children from vertical transmission and may lead to immune-based therapy to prevent vertical transmission of HTLV-I.

\section{Acknowledgments}

This study was supported in part by Grant-in-Aids for Cancer Research by the Ministry of Education, Science and Culture, Japan, and Personnel Exchange Program under the U.S.-Japan Cooperative Cancer Research Program by Japan Society for the Promotion of Science.

\section{References}

1. Tajima, K., and Y. Hinuma. 1992. Epidemiology of HTLV-I/II in Japan and the world. Gann Monogr. Cancer Res. 39:129-150.

2. Höllsburg, P., and D. A. Hafler. 1993. Pathogenesis of diseases induced by human lymphotropic virus type I infection. N. Engl. J. Med. 328:1173-1182.

3. Yamaguchi, K. 1994. Human T-lymphotropic virus type I in Japan. Lancet. 343:213-216

4. Hino, S., K. Yamaguchi, S. Katamine, H. Sugiyama, T. Amagasaki, K. Kinoshita, Y. Yoshida, H. Doi, Y. Tsuji, and T. Miyamoto. 1985. Mother-to-child transmission of human T-cell leukemia virus type-I. Jpn. J. Cancer Res. 76:474480.

5. Kinoshita, K., K. Yamanouchi, S. Ikeda, S. Momita, T. Amagasaki, H. Soda, M. Ichimaru, R. Moriuchi, S. Katamine, T. Miyamoto, and S. Hino. 1985. Oral infection of human T-cell leukemia virus type-I (HTLV-I) into a common marmoset by fresh human milk of carrier mothers of HTLV-I. Jpn. J. Cancer Res. (Gann.). 76:1147-1153.

6. Hino, S., H. Sugiyama, H. Doi, T. Ishimaru, T. Yamabe, T. Tsuji, and T. Miyamoto. 1987. Breaking the cycle of HTLV-I transmission via carrier mothers' milk. Lancet. ii:158-159.

7. Kusuhara, K., S. Sonoda, K. Takahasi, K. Tokugawa, J. Fukushige, and K. Ueda. 1987. Mother-to-child transmission of human T-cell leukemia virus type I (HTLV-I): a fifteen year follow up study in Okinawa, Japan. Int. J. Cancer 40:755-757.

8. Ando, Y., S. Nakano, K. Saito, I. Shimamoto, M. Ichijo, T. Toyama, and Y. Hinuma. 1987. Transmission of adult T-cell leukemia retrovirus (HTLV-I) from mother to child: comparison of bottle-with breast-fed babies. Jpn. J. Cancer Res. 78:322-324.

9. Kinoshita, K., T. Amagasaki, S. Hino, H. Doi, K. Yamanouchi, N. Ban, S. Momita, S. Ikeda, S. Kamihira, M. Ichimaru, et al. 1987. Milk-borne transmission of HTLV-I from carrier mothers to their children. Jpn. J. Cancer Res. 78:674680 .

10. Nagamine, M., Y. Nakashima, S. Uemura, H. Takei, T. Toda, T. Maehama, H. Nakachi, and M. Nakayama. 1991. DNA amplification of human T lymphotropic virus type I (HTLV-I) proviral DNA in breast milk of HTLV-I carriers. $J$. Infect. Dis. 164:1024-1025.

11. Sugiyama, H., H. Doi, K. Yamaguchi, Y. Tsuji, T. Miyamoto, and S Hino. 1986. Significance of postnatal mother-to-child transmission of human Tlymphotropic virus type-I on the development of adult T-cell leukemia/ lymphoma. J. Med. Virol. 20:253-260.

12. Hino, S., H. Doi, H. Yoshikuni, H. Sugiyama, T. Ishimaru, T. Yamabe, Y. Tsuji, and T. Miyamoto. 1987. HTLV-I carrier mothers with high-titer antibody are at high risk as the source of infection. Jpn. J. Cancer Res. 78:1156-1158.
13. Sawada, T., J. Tohmatsu, T. Obara, A. Koide, S. Kamihira, M. Ichimaru, S. Kashiwagi, W. Kajiyama, N. Matsumura, K. Kinoshita, et al. 1989. High risk of mother-to-child transmission of HTLV-I in p40 ${ }^{\operatorname{tax}}$ antibody positive mothers. Jap. J. Cancer Res. 80:506-508.

14. Kashiwagi, S., W. Kajiyama, J. Hayashi, A. Noguchi, K. Nakashima, H. Nomura, H. Ikematsu, T. Sawada, S. Kida, and A. Koide. 1990. Antibody to p40 $0^{\operatorname{tax}}$ protein of human $\mathrm{T}$ cell leukemia virus 1 and infectivity. J. Infect. Dis. $161: 426-429$

15. Maeda, Y., J. Imai, H. Kiyokawa, M. Kanamura, and S. Hino. 1989. Performance certification of gelatin particle agglutination assay for anti-HTLV-I antibody: inconclusive positive results. Jpn. J. Cancer Res. 80:915-919.

16. Buckner, C., C. R. Roberts, S. K. H. Foung, J. Lipka, G. R. Reyes, K. Hadlock, L. Chan, R. A. Gongora-Biachi, B. Hjelle, and R. B. Lal. 1992. Immune responsiveness to the immunodominant recombinant envelope epitopes of HTLVI and HTLV-II in diverse geographic populations. J. Infect. Dis. 166:1160-1163.

17. Lal, R. B., D. L. Rudolph, K. P. Griffis, K. Kitamura, M. Honda, J. E. Coligan, and T. M. Folks. 1991. Characterization of immunodominant epitopes of gag and pol gene encoded proteins of human T lymphotropic virus type-I. $J$. Virol. 65:1870-1876.

18. Rudolph, D. L., and R. B. Lal. 1993. Discrimination of human T-lymphotropic virus type-I and type-II infections by synthetic peptides comprising structural epitopes from the envelope glycoproteins. Clin. Chem. 39:288-292.

19. Rudolph, D. L., J. E. Coligan, and R. B. Lal. 1994. Detection of antibodies to trans-activator protein ( $\mathrm{p} 40^{\text {taxl }}$ ) of human $\mathrm{T}$-cell lymphotropic virus type $\mathrm{I}$ by a synthetic peptide-based assay. Clin. Diag. Lab. Immunol. 1:176-181.

20. Rudolph, D. L., R. F. Khabbaz, T. M. Folks, and R. B. Lal. 1993. Detection of human T-lymphotropic virus type-I/II $e n v$ antibodies by immunoassays using recombinant fusion proteins. Diag. Microbiol. Infect. Dis. 17:35-39.

21. Hartley, T. M., G. E. Malone, R. F. Khabbaz, R. B. Lal, and J. E. Kaplan. 1991. Evaluation of recombinant human T-cell lymphotropic virus type I (HTLVI) p21E antibody detection enzyme immunoassay as a supplementary test in HTLV-I/II antibody testing algorithms. J. Clin. Microbiol. 29:1125-1127.

22. Kawase, K., S. Katamine, R. Moriuchi, T. Miyamoto, K. Kubota, H. Igarashi, H. Doi, Y. Tsuji, T. Yamabe, and S. Hino. 1992. Maternal transmission of HTLV-I other than breast milk: detection of proviral DNA by polymerase chain reaction in the cord blood not indicative of intrauterine infection. Jpn. $J$. Cancer Res. 83:968-977.

23. Gessain, A., E. Boeri, R. Yanagihara, R. C. Gallo, and G. Franchini. 1993. Complete nucleotide sequence of a highly divergent human $\mathrm{T}$-cell leukemia (lymphotropic) virus type I (HTLV-I) variant from Melanesia: genetic and phylogenetic relationship to HTLV-I strains from other geographic regions. J. Virol. 67:1015-1023.

24. Wiktor, S. Z., E. J. Pate, E. L. Murphy, T. J. Palker, E. Champegnie, A. Ramlal, B. Cranston, B. Hanchard, and W. A. Blattner. 1993. Mother-to-child transmission of human T-cell lymphotropic virus type I (HTLV-I) in Jamaica: association with antibodies to envelope glycoprotein (gp46) epitopes. J. Acquired Immun. Defic. Syndr. 6:1162-1167.

25. Ishihara, S., A. Okayama, S. Stuver, H. Horinouchi, S. Shioiri, K. Murai, T. Kubota, R. Yamashita, N. Tachibana, H. Tsubouchi, and N. Mueller. 1994 Association of HTLV-I antibody profile of asymptomatic carriers with proviral DNA levels of peripheral blood mononuclear cells. J. Acquir. Immune Defic. Syndr. 7:199-203.

26. Jacobson, S., J. Reubin, R. Streilein, and T. Palker. 1991. Induction of $\mathrm{CD}^{+}{ }^{+}$, HTLV-I specific cytotoxic T lymphocytes from patient with HAM/TSP: recognition of an immunogenic region of the gp46 envelope glycoprotein of HTLV-I. J. Immunol. 146:1155-1162.

27. Tanaka, Y., L. Zeng, H. Shiraki, H. Shida, and H. Tozawa. 1991. Identification of a neutralization epitope on the envelope gp46 antigen of human $\mathrm{T}$ cell leukemia virus type $I$ and induction of neutralizing antibody by peptide immunization. J. Immunol. 147:354-360.

28. Kuroki, M., M. Nakamura, Y. Itoyama, Y. Tanaka, H. Shiraki, E. Baba T. Esaki, T. Tatsumoto, S. Nagafuchi, S. Nakano, and Y. Niho. 1992. Identification of new epitopes recognized by human monoclonal antibodies with neutralizing and antibody-dependent cellular cytotoxicity activities specific for human $\mathrm{T}$ cell leukemia virus type 1. J. Immunol. 149:940-948.

29. Sawada, T., Y. Iwahara, K. Ishi, H. Taguchi, H. Hoshino, and I. Miyoshi. 1991. Immunoglobulin prophylaxis against milkborne transmission of human $T$ cell leukemia virus type I in rabbits. J. Infect. Dis. 164:1193-1196.

30. Takahashi, K., T. Takezaki, T. Oki, K. Kawakami, S. Yashiki, T. Fujiyoshi, K. Usuku, N. Mueller. The mother-to-child transmission study group, M. Osame K. Miyata, Y. Nagata, and S. Sonoda. 1991. Inhibitory effect of maternal antibody on mother-to-child transmission of human T-lymphotropic virus type I. Int. J. Cancer. 49:673-677.

31. Zacharopoulos, V. R., M. E. Perotti, and D. M. Phillips. 1992. Lymphocyte-facilitated infection of epithelia by human T-cell lymphotropic virus type I. J. Virol. 66:4601-4605. 